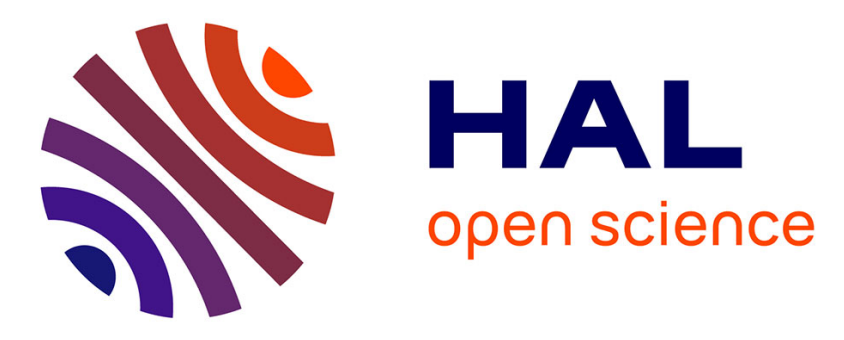

\title{
Changes in Bacterial Diversity, Composition and Interactions During the Development of the Seabird Tick Ornithodoros maritimus (Argasidae)
}

Yann Gomard, Olivier Flores, Marion Vittecoq, Thomas Blanchon, Céline Toty, Olivier Duron, Patrick Mavingui, Pablo Tortosa, Karen Mccoy

\section{To cite this version:}

Yann Gomard, Olivier Flores, Marion Vittecoq, Thomas Blanchon, Céline Toty, et al.. Changes in Bacterial Diversity, Composition and Interactions During the Development of the Seabird Tick Ornithodoros maritimus (Argasidae). Microbial ecology, 2020, 81 (3), pp.770-783. 10.1007/s00248020-01611-9 . hal-02961633

\section{HAL Id: hal-02961633 \\ https://hal.univ-reunion.fr/hal-02961633}

Submitted on 8 Oct 2020

HAL is a multi-disciplinary open access archive for the deposit and dissemination of scientific research documents, whether they are published or not. The documents may come from teaching and research institutions in France or abroad, or from public or private research centers.
L'archive ouverte pluridisciplinaire HAL, est destinée au dépôt et à la diffusion de documents scientifiques de niveau recherche, publiés ou non, émanant des établissements d'enseignement et de recherche français ou étrangers, des laboratoires publics ou privés. 


\title{
Changes in Bacterial Diversity, Composition and Interactions During the Development of the Seabird Tick Ornithodoros maritimus (Argasidae)
}

\author{
Yann Gomard ${ }^{1}$ - Olivier Flores ${ }^{2} \cdot$ Marion Vittecoq $^{3} \cdot$ Thomas Blanchon $^{3} \cdot$ Céline Toty $^{1,4}$ - Olivier Duron ${ }^{4,5} \cdot$ Patrick $^{4}$
} Mavingui ${ }^{1} \cdot$ Pablo Tortosa $^{1} \cdot$ Karen D. McCoy ${ }^{4,5}$

\begin{abstract}
Characterising within-host microbial interactions is essential to understand the drivers that shape these interactions and their consequences for host ecology and evolution. Here, we examined the bacterial microbiota hosted by the seabird soft tick Ornithodoros maritimus (Argasidae) in order to uncover bacterial interactions within ticks and how these interactions change over tick development. Bacterial communities were characterised through next-generation sequencing of the V3-V4 hypervariable region of the bacterial 16S ribosomal RNA gene. Bacterial co-occurrence and coexclusion were determined by analysing networks generated from the metagenomic data obtained at each life stage. Overall, the microbiota of $O$. maritimus was dominated by four bacterial genera, namely Coxiella, Rickettsia, Brevibacterium and Arsenophonus, representing almost $60 \%$ of the reads. Bacterial diversity increased over tick devel-opment, and adult male ticks showed higher diversity than

did adult female ticks. Bacterial networks showed that co-occurrence was more frequent than co-exclusion and highlighted substantial shifts across tick life stages; interaction networks changed from one stage to the next with a steady increase in the number of interactions through development. Although many bacterial interactions appeared unstable across life stages, some were maintained throughout develop-ment and were found in both sexes, such as Coxiella and Arsenophonus. Our data support the existence of a few stable interactions in O. maritimus ticks, on top of which bacterial taxa accumulate from hosts and/or the environment during development. We propose that stable associations delineate core microbial interactions, which are likely to be respon-sible for key biological functions.
\end{abstract}

Keywords Ornithodoros maritimus $\cdot$ Bacterial interactions $\cdot$ Network analyses $\cdot 16 \mathrm{~S}$ rRNA gene

Pablo Tortosa and Karen D. McCoy contributed equally to this work.

Electronic supplementary material The online version of this article (https://doi.org/10.1007/s00248 02001611 9) contains supplementary material, which is available to authorized users.

Yann Gomard

yann.gomard@gmail.com

Université de La Réunion, UMR PIMIT (Processus Infectieux en Milieu Insulaire Tropical), INSERM 1187, CNRS 9192, IRD 249 , Plateforme Technologique CYROI, Sainte Clotilde, La Réunion, France

2 Université de La Réunion, UMR PVBMT (Peuplements Végétaux et Bioagresseurs en Milieu Tropical), CIRAD, Saint Pierre, La Réunion, France
3 Tour de Valat, Research Institute for the Conservation of Mediterranean Wetlands, Arles, France

4 MIVEGEC, University of Montpellier CNRS IRD, Centre IRD, Montpellier, France

5 Centre for Research on the Ecology and Evolution of Diseases (CREES), Montpellier, France 


\section{Introduction}

Symbiotic associations between microorganisms and their invertebrate hosts, where partners share essential biological functions and work as a holobiont, are the subject of an increasing number of studies [1, 2]. However, identifying these associations can be difficult given the general richness of the microbiome in most individuals. Quantifying within-host variation in microbial composition over time can help detect these associations, along with the drivers that shape them. Such studies require multifaceted investigations that target different aspects of the host biology and ecology and take into account changing environmental conditions [3].

In arthropods, essential microbial interactions required for completion of the host life cycle have been repeatedly demonstrated, but most investigations focus on one or a limited number of microbial taxa, particularly obligate endosymbionts [4-6]. The advent of next-generation sequencing (NGS) technologies has led to major advances in the characterisation of microbiota [7-10]. These technologies enable the description of microbial communities in terms of both taxonomic diversity and relative abundance. They also allow us to infer microbial interactions using positive and negative correlations between the numbers of reads obtained for each bacterial taxon $[11,12]$ and can be explored in related host species or within a single host species throughout its development. For example, Hegde et al. [12] have shown that bacterial network associations in the mosquitoes Aedes albopictus and Culex quinquefasciatus are less complex than in Aedes aegypti. Interestingly, this study also demonstrated that some bacterial interactions were common to several mosquito species and stable regardless of the environment, while others appeared more dynamic [12].

Ticks (order: Ixodida) are haematophagous ectoparasites that exploit a large range of vertebrate hosts (i.e. reptiles, birds and mammals, including humans) and are distributed across the globe [13]. They represent an important group of vectors and transmit numerous diseases of significant importance for animal and human populations (e.g. Lyme disease, relapsing fever, Crimean-Congo haemorrhagic fever virus, etc.) [13, 14]. Given the medical and veterinary importance of ticks, understanding the diversity of their microbiota and the nature of within-holobiont interactions (i.e. among microbiota and between host and microbiota) may provide tools for the control of tick-borne diseases $[15,16]$. Although relatively few NGS studies have examined tick microbiomes to date, most of these focus on bacterial communities sheltered by hard ticks (family: Ixodidae) [7, 16, 17], and little is known about these communities in soft ticks (family: Argasidae) [18-20]. These NGS studies have shown that tick microbiota include a remarkable diversity of endosymbiotic, commensal and pathogenic bacteria. Some bacterial taxa are overwhelmingly dominant and considered as essential endosymbionts in several tick species
[7, 16, 21, 22]. Among these genera, Coxiella and Francisella have been shown to play a key role in tick biology by provisioning essential nutrients [18, 23-25]. In addition to Coxiella and Francisella, many other maternally inherited bacteria, such as Arsenophonus and Cardinium, are present in ticks. Although their action in the host remains to be documented, these bacteria are usually considered facultative symbionts [21, $22]$, exhibiting variable infection frequencies in tick populations across diverse temporal and spatial scales [22]. While facultative symbionts are not required for host survival, they are known to encode essential traits in many arthropods: some manipulate reproduction to favour their transmission, while others protect their host against natural enemies or facilitate adaptation to changing environments [5, 26]. As hosts can vary in the number and types of facultative symbionts they harbour, heritable and functionally important phenotypic variation can exist within arthropod populations [27, 28].

Tick bacterial assemblages studied to date have been shown to vary according to different biological factors such as species, life stage, age and sex, as well as by the investigated tissue and environmental conditions [7, 29-41]. However, few studies have thus far investigated bacterial interactions within ticks [33, 42-45], with the exception of those focusing on obligate symbionts (e.g. [14]). An analysis of Ixodes ricinus microbiota suggested that virtually no bacterial genus is required for the co-occurrence of another genus [43]. However, both negative and positive interactions (i) between endosymbionts, (ii) between vertebrate pathogens (referred herein as pathogens) and (iii) between endosymbionts and pathogens have been reported in ticks. For instance, Duron et al. [22] detected co-occurrence and mutual exclusion patterns within the symbiotic bacterial communities of 81 tick species. Francisella and Rickettsia endosymbionts appeared mutually exclusive in Dermacentor occidentalis [44], and exclusion patterns were demonstrated for Francisella and Coxiella endosymbionts on different Amblyomma species [46]. Moutailler et al. [47] reported a positive association between the Lyme disease pathogens Borrelia garinii and Borrelia afzelii in I. ricinus. In D. andersoni, Gall et al. [48] found a negative correlation between the endosymbiont Rickettsia bellii and the pathogen Anaplasma marginale and a positive correlation between Francisella endosymbionts and the pathogen Francisella novicida. Previous studies also reported exclusion between symbiotic and pathogenic Rickettsia $[49,50]$. Understanding the nature of these interactions is thus complex and, as of yet, incomplete.

The purpose of the present study was to characterise the bacterial microbiota associated with the soft tick Ornithodoros maritimus (family: Argasidae) and to examine the nature of bacterial interactions according to life stage (i.e. larva, nymph and adult). O. maritimus is a nidicolous soft tick species (Fig. 1) living in or around the nests of their seabird hosts [51], where all life stages co-occur. These ticks feed on birds 
Fig. 1 Ornithodoros maritimus ticks from the islet of Carteau. a Dorsal and $\mathbf{b}$ ventral views of a non engorged adult female. $\mathbf{c}$ Ventral view of an adult male. The red arrows indicate the gon opore of each specimen showing the sex specific shape, females with diamond shaped gonopores and males with oval shaped gon opores. d $O$. maritimus in a yellow legged gull (Larus michahellis) nest indicated by yellow arrows. e A yellow legged gull chick and egg in a nest on Carteau. All photo credits: M. Dupraz
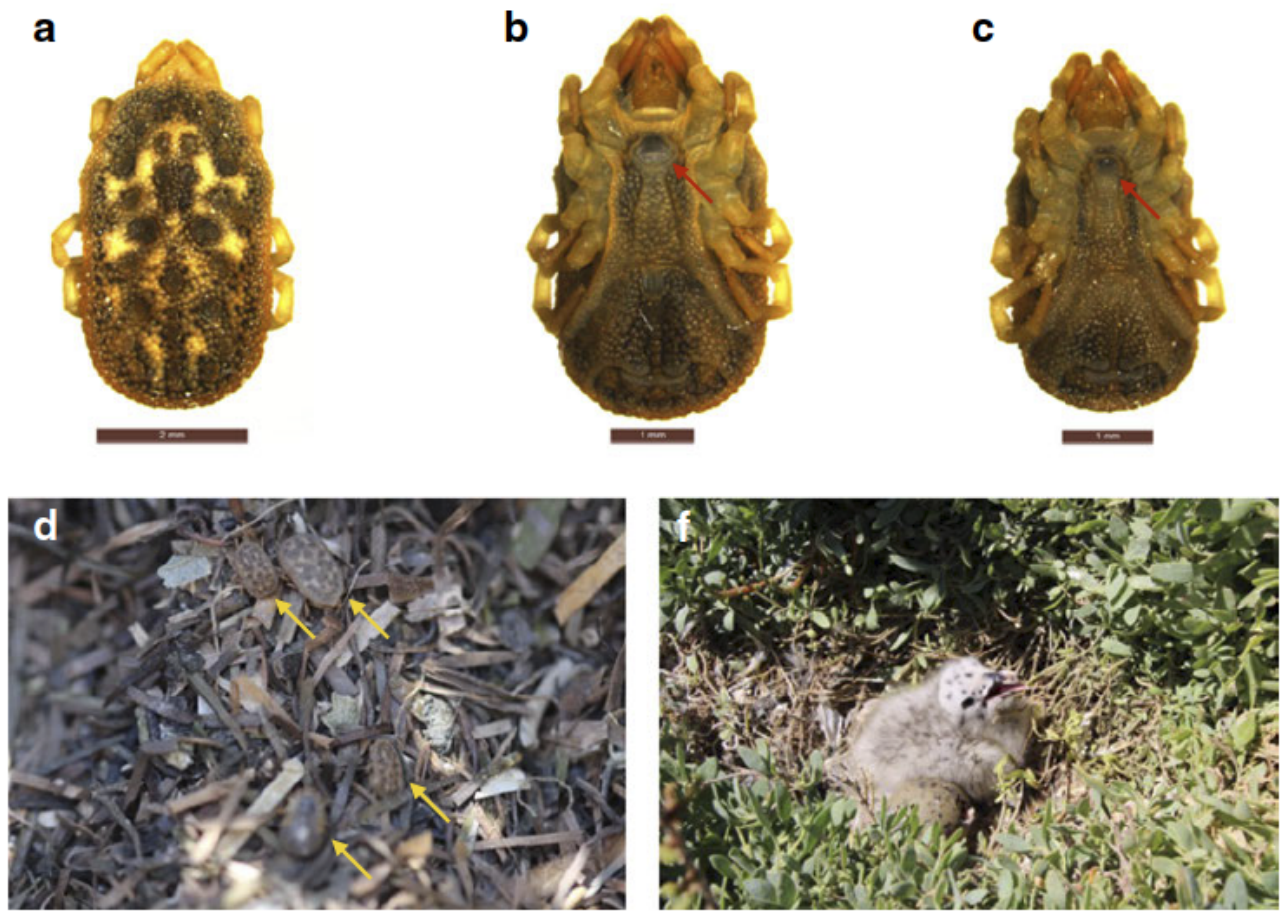

during resting periods, generally at night, taking numerous short bloodmeals on the host as nymphs and adults (several minutes to $1 \mathrm{~h}$ ) and one relatively long bloodmeal (several hours) in the larval stage [52]. Reported from southern Great Britain to North Africa, O. maritimus has been recorded parasitising a large range of seabird species (auks, cormorants, gulls, kittiwake, petrels and sterns) [53, 54]. Hyperinfestations by $O$. maritimus have been associated with negative effects on some seabird species, but the overall impact of these ticks on host fitness is poorly studied [55-57]. Likewise, although known human and animal pathogens have been reported from O. maritimus (e.g. Borrelia turicatae, Soldado and West Nile viruses), knowledge on the effect of these bacteria on birds is lacking [53]. Several other bacteria, phylogenetically related to known pathogens, may also have pathogenic potential, but require more study [22, 52, 57-62].

We sampled different life stages of Ornithodoros maritimus from a single breeding colony of the Yellowlegged gull (Larus michahellis) found on the islet of Carteau in the Gulf of Fos (Camargue region, Southern France). This sampling scheme enabled us to collect ticks within a relatively closed system, controlling for factors such as host preference (only one host species present), seasonality (sampling over a 6-week period) and geographic scale (one small and homogeneous island). In addition, a previous study suggested no structure in the presence of targeted infectious agents in adult female ticks among nests within this colony [52]. Thus, we hypothesised that any differences in tick bacterial communities and interactions would be related to changes over the course of tick development. Using 16S ribosomal RNA
Illumina sequencing, we first described the bacterial microbiota sheltered by field-collected ticks. We then tested whether the developmental stage (larva, nymph and adult) and/or sex influenced the bacterial microbiota composition. Finally, we constructed bacterial networks and examined co-occurrence in order to understand how bacterial interactions shift through tick development and across sexes.

\section{Materials and Methods}

\section{Tick Collection}

The ticks used in the present work were sampled in the context of a study on the seasonal dynamics of Ornithodoros maritimus and its associated pathogens; see Dupraz et al. [52]. In this study, the authors sampled ticks from 30 yellow-legged gull nests in the colony of Carteau during a single breeding season (GPS coordinates: $\left.43^{\circ} 22^{\prime} 39^{\prime \prime} \mathrm{N} 4^{\circ} 51^{\prime} 28^{\prime \prime} \mathrm{E}\right)$. Carteau is a small sandy islet within the Gulf of Fos that harbours a monospecific yellow-legged gull-breeding colony. Ticks were collected between March and May 2015 with one collection session per week during six successive weeks. Following collection, the ticks were stored in $70 \%$ ethanol and brought back to the lab where they were morphologically identified based on classical criteria [54]. The sex of adult ticks was determined based on gonopore shape (Fig. 1). The ticks then were kept frozen at $-20{ }^{\circ} \mathrm{C}$ until nucleic acid extraction and molecular analyses. A 
subsample of 50 specimens from this tick collection was used in the present study and corresponded to 11 larvae, 12 nymphs and 27 adults (14 females and 13 males).

\section{DNA Extraction, 16S Ribosomal RNA Gene Sequencing and Bioinformatic Analyses}

Each tick was rinsed in two successive baths of sterile water to remove ethanol. Whole ticks were individually crushed in a 1.5-mL tube containing $180 \mu \mathrm{L}$ of ATL buffer and incubated overnight at $56^{\circ} \mathrm{C}$ with $20 \mu \mathrm{L}$ of proteinase $\mathrm{K}$. DNA was then extracted using a Qiagen DNeasy Blood and Tissue Kit (Qiagen, Les Ulis, France) following the manufacturer's recommendations. One negative control was included in the extraction protocol to identify DNA contaminations produced during the extraction process.

The bacterial microbiota of each tick was investigated through deep sequencing of the V3-V4 hypervariable region of the bacterial 16S ribosomal RNA gene (16S rRNA gene). In summary, the V3-V4 region (V3, forward primer: 5'TACGGRAGGCAGCAG-3' and V4, reverse primer: 5'CTACCNGGGTATCTAAT-3') was amplified from $5 \mathrm{ng}$ of DNA from each sample and the negative DNA extraction control following the Metabiote $\AA$ protocol for a standard amplicon library preparation (Genoscreen, Lille, France). A positive and a negative PCR control, corresponding to an assemblage of known bacteria and pure water, respectively, were added during library preparation by Genoscreen. The final amplification products (each containing a nucleotide index to differentiate the samples, as well as the adapters necessary for carrying out the sequencing) were purified on beads and then mixed in equal concentrations. Sequencing was realized with a $2 \times 250$-bp paired-end chemistry using Illumina MiSeq technology (Genoscreen, Lille, France). The Illumina's CASAVA software 1.8 was used to de-multiplex the sequence reads and produce fastq files. Primers were removed, and sequences were trimmed when the Phred quality score (Q score) was inferior to 30. Assembly of the two-paired sequences was realized with the FLASH tool [63], with a minimum overlap of 30 bases and at least $97 \%$ identity in the overlapping area. The generated sequences were analysed with the software MOTHUR (version 1.35.1) [64] following the MiSeq SOP protocol [65]. Briefly, we retained sequences presenting (i) a size comprised between 400 and $440 \mathrm{bp}$, (ii) no ambiguous bases and (iii) a maximum of eight homopolymers. Chimeras were removed from the analysis with UCHIME [66]. Operational taxonomic units (OTUs) were generated based on $97 \%$ sequence similarity using the OptiClust clustering method [67]. The SILVA database release 138 [68] was used for sequence alignments and taxonomical assignments of OTUs. The estimated Good's coverage [69] was calculated in MOTHUR in order to check the representation of the bacterial community in each sample; an index superior to 0.97 indicates a satisfactory per sample sequencing depth. As described in Minard et al. [9] and RenéMartellet et al. [37], we removed all OTUs from the analysis for which the relative abundance was not at least ten times superior to that detected in negative extraction and PCR controls. OTUs represented by only one sequence were removed from the analysis. Finally, sequences were proportionally normalised to the sample with the smallest number of reads ( $n=$ 2814 reads). For an overview of the bioinformatics workflow, see Online Resource 1 Fig. S1.

\section{Bacterial Diversity and Community Structure}

We assessed alpha diversity at the OTU level and performed non-parametric comparisons between the different tick life stages, i.e. larvae, nymphs and adults (three groups). In addition, we performed comparisons between sexes in adult ticks (two groups). Previous studies indicated that the relatively high abundance of Rickettsia in female ticks could explain low bacterial diversity in this sex [39, 40]. To test this hypothesis, we compared the alpha bacterial diversity between male and female ticks with three additional datasets, corresponding to data with the dominant taxa removed: (i) Rickettsia sequences removed, (ii) Coxiella sequences removed and (iii) both Rickettsia and Coxiella sequences removed (Online Resource 1 Fig. S1). Alpha diversity was evaluated using Shannon's diversity index, which was converted into an equivalent number of species [70]. Differences in alpha diversity across tick life stages were tested with a Kruskal-Wallis test, followed by post-hoc pairwise comparisons to assess the significance of differences between each tick life stage. The pairwise comparison tests were realised using the function "kruskalmc" from the R package "pgirmess" [71]. For sex, differences in alpha diversity were tested using Wilcoxon tests. To examine differences in community composition among life stages, non-metric multidimensional scaling (NMDS) ordination based on Bray-Curtis dissimilarities was performed. In order to test if microbial communities differ according to the life stage or sex, we then performed permutational multivariate analysis of variance (PerMANOVA) on the Bray-Curtis dissimilarities. All analyses were performed using the $\mathrm{R}$ software (version 3.4.3) [72] . We used a linear discriminant analysis (LDA) of effect size (LEfSe) [73] under Galaxy (http://huttenhower.sph.harvard.edu/lefse/) to identify bacterial genera whose relative abundance significantly differed according to life stage and sex, and that best discriminated each tick group ( $p$ value $\leq 0.05$ and LDA score $>2.0$ ).

\section{Bacterial Network Analyses}

One bacterial network was generated at the genus level for each tick life stage (larva, nymph and adult) and sex in adults. 
For each of the five groups, network construction was performed using bacterial taxa present in at least $50.0 \%$ of tick specimens and whose relative abundance was superior to $0.1 \%$ of reads in order to discard rare taxa in the generated data. Based on the procedure described by Faust and Raes [74], bacterial networks were generated using CoNet plug-in (version 1.1.1.beta) [74] implemented in Cytoscape (version 3.3.0) [75]. Significant associations were identified using five methods: two correlation methods (Pearson and Spearman), two dissimilarity distance methods (Bray-Curtis and Kullback-Leibler) and mutual information similarity. The $p$ values calculated for all methods were merged using Brown's method [76], and false-discovery rates were corrected using Benjamini and Hochberg's procedure [77]. Finally, bacterial associations in the networks were represented as either co-occurrence (positive correlation) or coexclusion (negative correlation) considered herein as positive or negative interactions, respectively. Investigating the presence of significant interactions and their sign across the different groups allowed us to detect changes in bacterial interactions over tick development and in relation to sex.

\section{Results}

\section{Bacterial Diversity and Community Structure}

For each sample, a Good's coverage index superior to 0.98 was obtained, indicating a satisfactory representation of the bacterial assemblage present in the samples (Table 1 and Online Resource 2 Table S1). In negative PCR and DNA extraction controls, 11 sequences (represented by 5 OTUs) and 17,998 sequences (represented by 37 OTUs) were detected, respectively (Online Resource 2 Table S2). In the negative DNA extraction control, $75.1 \%$ and $11.7 \%$ of the sequences were classified as Escherichia Shigella and Sphingomonas, respectively. These genera have been previously reported as contaminants $[78,79]$. Thus, based on our cleaning criteria, we removed a total of 38 OTUs (represented by 104,716 reads) from the tick sample (Online Resource 2 Table S3). The remaining 4 OTUs were not removed from the data, as their relative abundance was ten times higher in ticks compared with controls. We also removed 1819 OTUs represented by a single read (Online Resource 2 Tables S4 and S5). Finally, after the different bioinformatic cleaning steps, a total of 886,359 reads were retained from the sampled ticks, with a mean of 17,727 reads per specimen (range 2814-26,748) (Online Resource 2 Table S5). Based on the normalised data, the phyla Proteobacteria (71.0\%), Actinobacteria (13.8\%), Firmicutes $(9.4 \%)$ and Bacteroidetes $(5.4 \%)$ represented more than $99.0 \%$ sequences. Sequences were distributed into 2575 OTUs and 864 genera among which four, namely Coxiella, Rickettsia, Brevibacterium and Arsenophonus, accounted for almost $60 \%$ of all sequences. Coxiella (37.0\% of reads), Rickettsia (10.8\% of reads), Brevibacterium (6.6\% of reads) and Arsenophonus (5.5\% of reads) were detected in $100.0 \%$, $96.0 \%, 98.0 \%$ and $90.0 \%$ of the specimens, respectively (Fig. 2 and Online Resource 2 Table S6). The relative abundance of each genus varied at the individual level (Fig. 2). Sequences belonging to Coxiella were represented mainly by one OTU whose $16 \mathrm{~S}$ sequence corresponded to the Coxiella endosymbiont previously reported in $O$. maritimus [58]. The genera Kocuria and Rickettsiella were detected in our data with 330 and 28 sequences respectively, based on normalised data. The genera Wolbachia was considered as absent with only 1 sequence reported from the normalised data. In addition, none of the following previously described tick-associated bacteria was found in our samples: Anaplasma, Bartonella, Borrelia, Cardinium, Ehrlichia, Francisella, Lariskella, Midichloria and Spiroplasma.

Alpha diversity increased significantly with life stage $(n=$ 50, Kruskal-Wallis test, $X^{2}=11.579, \mathrm{df}=2, p$ value $\left.<0.005\right)$ with larvae, nymphs and adults presenting average Shannon number-equivalent diversity values of $7.33 \pm 5.44,16.58 \pm$ 24.81 and 23.54 \pm 22.19 , respectively (Table 1). Multiple comparison tests indicated that alpha diversity was significantly different between larvae and adults (post-hoc Kruskal-Wallis, $p$ value $<0.05$ ), nymphs and adults (post-hoc Kruskal-Wallis, $p$ value $<0.05$ ), but not between larvae and nymphs (post-hoc Kruskal-Wallis, $p$ value $>0.05$ ). Within adults, alpha diversity differed according to sex $(n=27$, Wilcoxon test, $\mathrm{W}=12, p$ value $<0.001$ ), with males displaying higher bacterial diversity (average Shannon diversity index $=37.68 \pm 24.72$ ) than females (average Shannon diversity index $=10.40 \pm 4.01$ ) (Table 1). Relative sample sizes did not seem to be an issue for these analyses; power analyses, using the "kwpower"

Table 1 Summary of Good's coverage index, OTUs and Shannon number equivalent diversity obtained for the microbiota of $O$. maritimus

\begin{tabular}{lllcc}
\hline Type & Good's coverage index & Total OTUs detected & Average number OTUs/sample & Shannon number equivalent diversity \\
\hline Larvae $(n=11)$ & $0.998 \pm 0.001$ & 345 & $57.27 \pm 30.26$ & $7.33 \pm 5.44$ \\
Nymphs $(n=12)$ & $0.995 \pm 0.005$ & 1382 & $234.25 \pm 185.94$ & $16.58 \pm 24.81$ \\
Adults $(n=27)$ & $0.994 \pm 0.003$ & 2185 & $359.41 \pm 161.90$ & $23.54 \pm 22.19$ \\
Males $(n=13)$ & $0.991 \pm 0.003$ & 1929 & $473.92 \pm 128.80$ & $37.68 \pm 24.72$ \\
Females $(n=14)$ & $0.996 \pm 0.002$ & 1236 & $253.07 \pm 107.00$ & $10.40 \pm 4.91$ \\
\hline
\end{tabular}




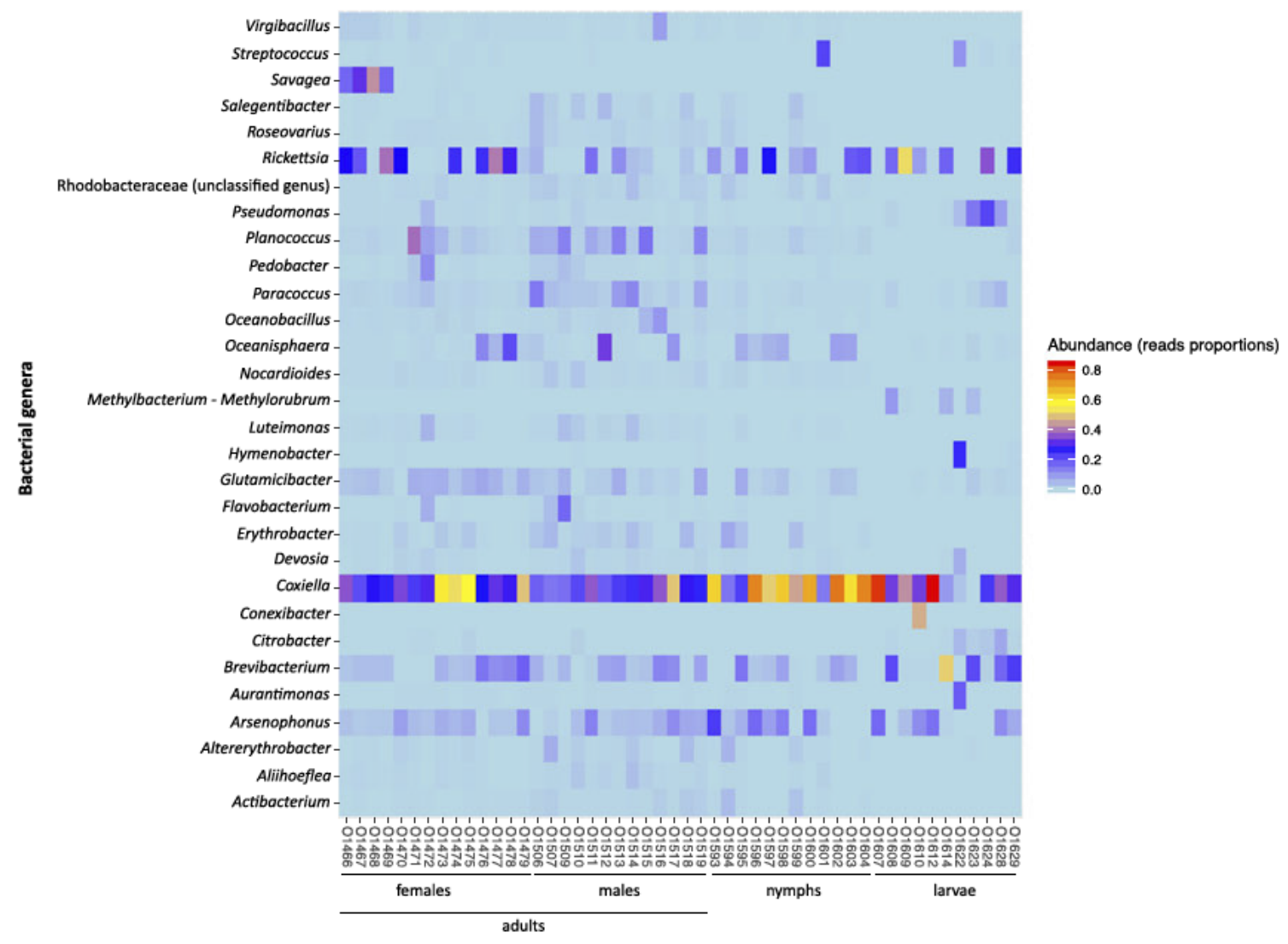

Fig. 2 Heatmap of the top 30 genera detected in O. maritimus according to tick life stage and sex

function of the "MultNonParam" $\mathrm{R}$ package [80], revealed an estimated power above 0.95 when observed diversity values were used as estimates for effect sizes, but also when effect sizes were lowered by one order of magnitude. In silico removal of Rickettsia and/or Coxiella sequences did not change the results as alpha diversity remained significantly higher in males compared with females for all datasets (without Rickettsia sequences: $n=27$, Wilcoxon test, $\mathrm{W}=14, p$ value $<0.001$; without Coxiella sequences: $n=$ 27 , Wilcoxon test, $\mathrm{W}=21, p$ value $<0.001$; without Rickettsia and Coxiella sequences: $n=27$, Wilcoxon test, $\mathrm{W}=29, p$ value $<0.01$ ).

Bacterial communities were significantly structured across tick life stages $($ PerMANOVA, $\mathrm{F}$-stat $=4.03, \mathrm{df}=2, p$ value $=$ 0.001), between larvae and nymphs (PerMANOVA, F-stat $=$ $2.65, \mathrm{df}=1, p$ value $=0.015$ ), between larvae and adults (PerMANOVA, F-stat $=4.74, \mathrm{df}=1, p$ value $=0.001)$ and between nymphs and adults (PerMANOVA, F-stat $=4.23, \mathrm{df}=$ $1, p$ value $=0.001)($ Fig. 3a, Online Resource 1 Fig. S2). Within adults, the bacterial community was also structured according to sex (PerMANOVA, F-stat $=4.59, \mathrm{df}=1, p$ value $=0.001)($ Fig. 3b). Some tick specimens seemed to harbour the microbial community of the other sex (Fig. 3b); this pattern may result from mistakes in sexing adult specimens, which can occur for recently moulted ticks.
The LEfSe results indicated that the genus Devosia was more abundant in larvae while Tropicimonas and Lacticigenium genera were more abundant in nymphs (Fig. 4a). Compared with larvae and nymphs, 36 genera were found to be more abundant in adult ticks, such as Planococcus and Pedobacter. In adults, 135 genera were significantly more abundant in males compared with females, including Paracoccus, Planococcus and Erythrobacter, whereas only nine genera were significantly more abundant in females compared with males, including Coxiella, Savagea and Glutamicibacter (Fig. 4b).

\section{Bacterial Network Analyses}

The networks generated for the three life stages were largely dominated by positive interactions (Table 2, Online Resource 1 Figs. S3 and S4, Online Resource 3 Table S7). Indeed, cooccurrence represented $76 \%, 97 \%$ and $94 \%$ of the interactions detected in larval, nymphal and adult datasets, respectively. Similarly, within adults, co-occurrence represented $88 \%$ and $96 \%$ of the interactions reported respectively in females and males (Table 2). Network complexity (i.e. the number of nodes and edges) increased with life stage, with adults displaying the most complex network (60 nodes and 412 edges) relative to larvae (20 nodes and 66 edges) and nymphs 
a) Life stages

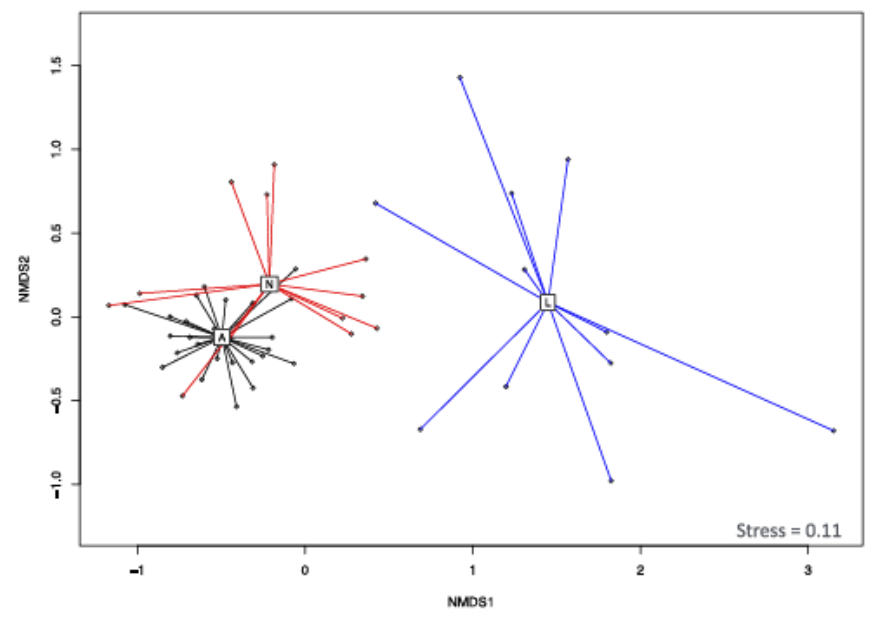

Fig. 3 Bacterial community composition according to life stage (a) and sex (b) of $O$. maritimus ticks. Non metric multidimensional scaling (NMDS) plots were produced from Bray Curtis distances of OTU matri ces. Each point in the NMDS plots corresponds to the microbiota of one

(55 nodes and 570 edges). Within adults, the network appeared less complex in females ( 54 nodes and 164 edges) than in males (62 nodes and 177 edges). The reported complexity

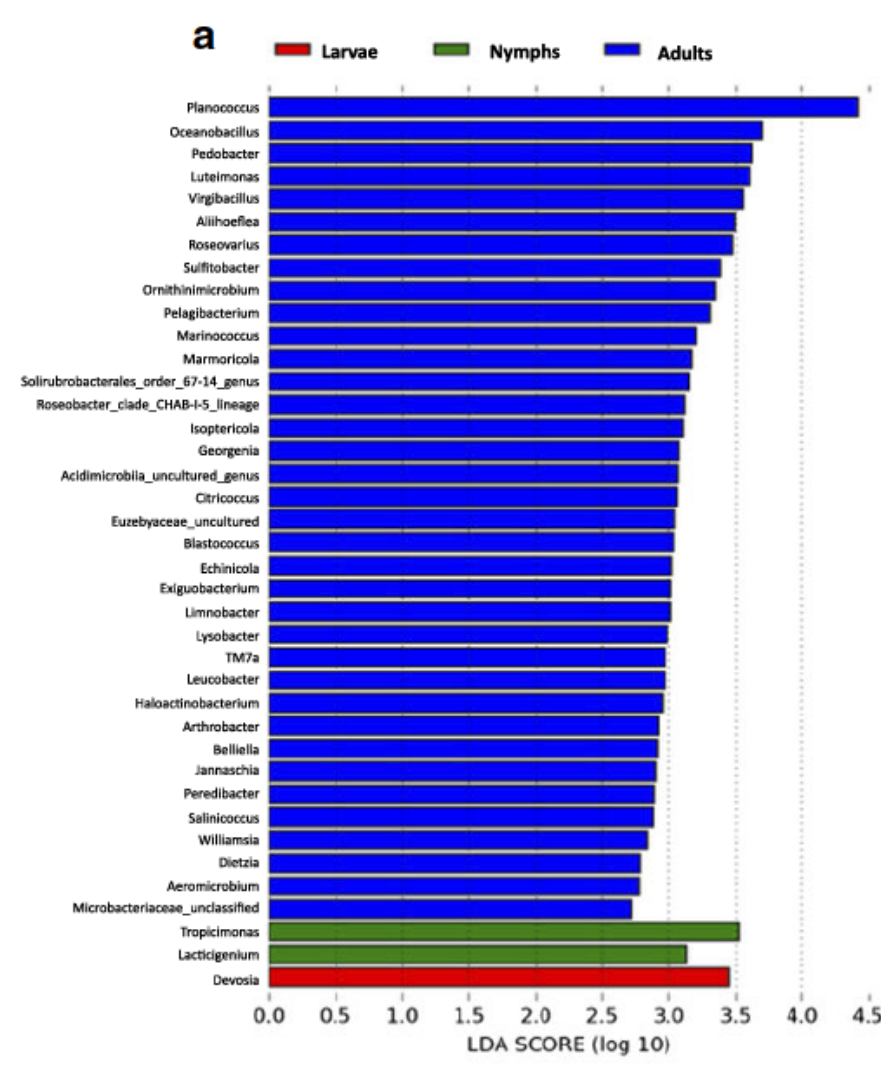

Fig. 4 The bacterial genera whose abundance differed according to tick life stage (a) and sex (b) of $O$. maritimus ticks. These results are based on LEfSe's analyses ( $p$ value $=0.05$ and LDA score $>2.0$ ). The red rectangle b) Sex

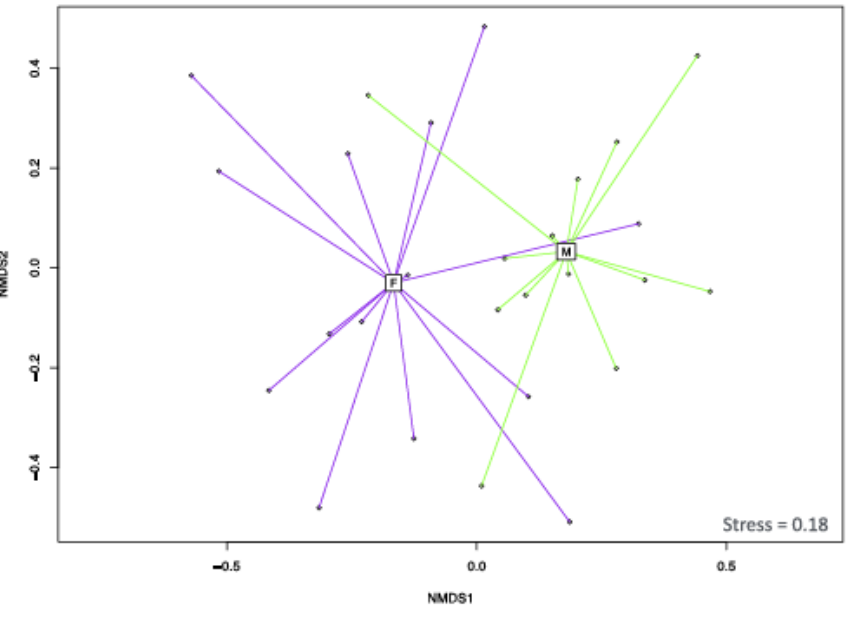

tick specimen. $\mathrm{L}$ larvae, $\mathrm{N}$ nymphs, A adults, $\mathrm{F}$ females and $\mathrm{M}$ males. The stress values of each plot are inferior to 0.2 indicating good representation

of the adult network could be due to the higher number of analysed specimens $(n=27)$ compared with larvae $(n=11)$ and nymphs $(n=12)$. However, larval and nymphal networks

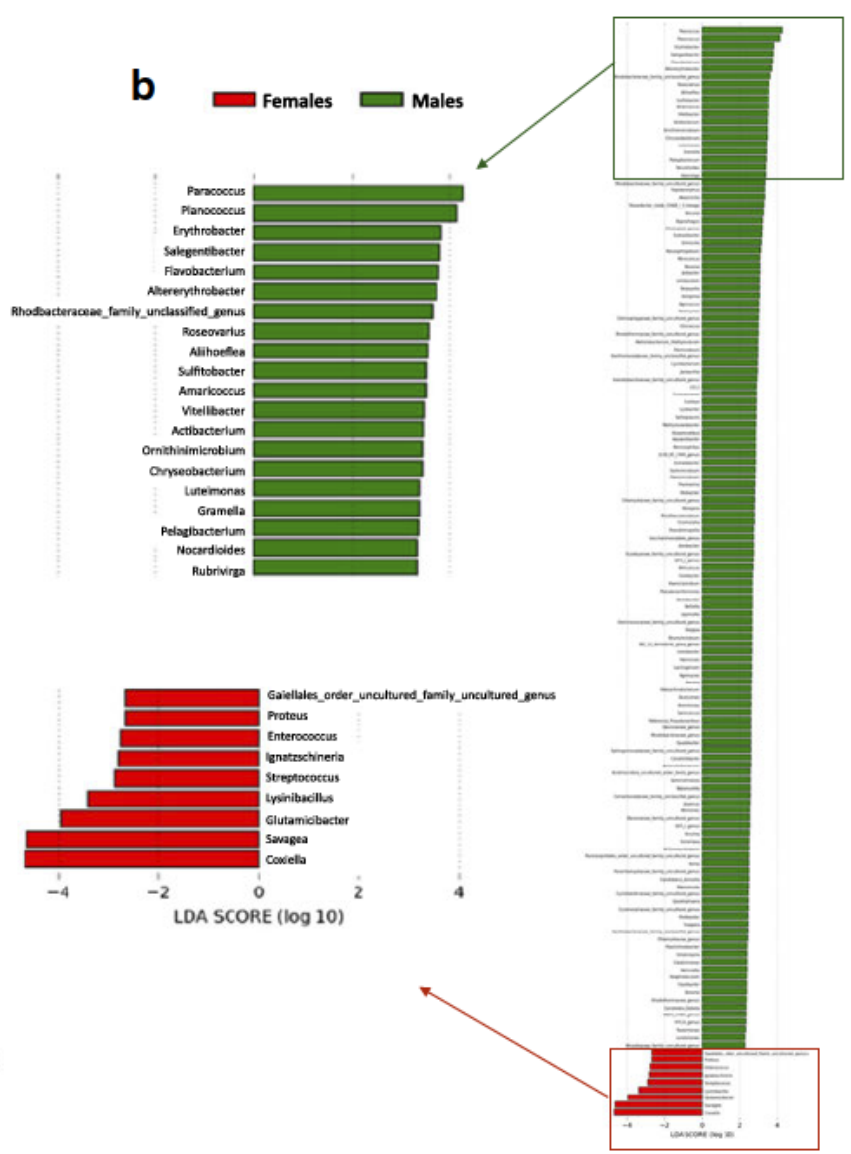

shows the 9 genera which are significantly more abundant in females than in males. The green rectangle highlights the top 20 genera which are significantly more abundant in males than in females 
Table 2 Details on bacterial networks produced from O. maritimus according to life stage and sex

\begin{tabular}{lllll}
\hline Life stage & $\begin{array}{l}\text { Number } \\
\text { of nodes }\end{array}$ & Number of edges & Number of co occurrences & Number of co exclusions \\
\hline Larva $(n=11)$ & 20 & 66 & 50 & 16 \\
Nymph $(n=12)$ & 55 & 570 & 555 & 15 \\
Adult $(n=27)$ & 60 & 412 & 388 & 24 \\
Male $(n=13)$ & 62 & 177 & 170 & 7 \\
Female $(n=14)$ & 54 & 164 & 144 & 20 \\
\hline
\end{tabular}

were based on comparable sample sizes and support the observation that network complexity increases with life stage.

At a finer level, the comparison of the different networks showed that bacterial interactions considerably changed between life stages and sexes (Online Resource 1 Figs. S3 and S4, Online Resource 3 Table S7). For instance, Rickettsia did not systematically display the same interactions in the networks obtained from larvae, adults and females (Online Resource 1 Figs. S3 and S4); no interaction with the genus Rickettsia was found in networks generated using nymphal and male datasets, whereas both positive and negative interactions were present in larval and female networks (Online Resource 1 Figs. S3 and S4, Online Resource 3 Table S7). In some cases, the interaction pattern (co-occurrence or coexclusion) changed according to the development stage. For example, co-exclusion was detected between Planococcus and Paracoccus in the larval network, whereas cooccurrence was reported in nymphal and adult networks (Online Resource 4 Table S8). Despite these differences, some bacterial taxa displayed the same type of interaction in most networks, suggesting that these interactions are stable across life stages and sexes. For instance, co-occurrence between Brevibacterium and Staphylococcus was detected in all five networks (Online Resource 4 Tables S8 and S9). Interestingly, co-occurrence between the endosymbionts Coxiella and Arsenophonus was detected in larvae and in adults, but not in nymphs (Online Resource 4 Table S8). No other interactions involving Coxiella and Arsenophonus were detected in adult ticks, with similar findings for the individual female and male datasets. In contrast, bacterial interactions involving Coxiella and Arsenophonus were detected in larvae and nymphs (Online Resource 1 Figs. S3 and S4).

Interestingly, the four most abundant bacterial genera (Coxiella, Rickettsia, Brevibacterium and Arsenophonus) did not display a higher number of interactions within the different networks than less abundant genera (Online Resource 5 Table S10). Indeed, the genus with the highest number of interactions varied according to tick life stage and sex. For instance, in larvae, Corynebacterium displayed the highest number of interactions (11 interactions), while 36 interactions were reported for the genus Aliihoeflea in nymphs. In adults, the genera Altererythrobacter, Novosphingobium and
Sulfitobacter displayed the highest number of interactions (27 interactions for each taxon). In females, Brevundimonas displayed the highest number of interactions (20 interactions), while in males, the highest number of interactions was reported for Euzebyella (16 interactions, Online Resource 5 Table S10). These genera appear as relatively central nodes in the corresponding networks, which may indicate important functional roles in microbial interactions.

\section{Discussion}

To date, few NGS studies have investigated the bacterial microbiota associated with soft tick species [18-20], and, to our knowledge, the present work constitutes the first NGS study of bacterial microbiota in Ornithodoros maritimus. The results reveal some similarities to the microbiota of hard tick species. For instance, we show that the microbial community of O. maritimus is dominated by the genera Coxiella, Rickettsia, Brevibacterium and Arsenophonus. The detection of Coxiella and Rickettsia is consistent with previous targeted studies on $O$. maritimus feeding on the same host species, Larus michahellis [22, 52, 58, 59], and is common to the majority of Ornithodoros spp. specimens tested to date [22]. Coxiella has been recently described as an obligate symbiont providing vitamin B to ticks [23-25]. Some Rickettsia species are also known to be maternally inherited symbionts, whereas others are vertebrate pathogens acquired horizontally [81, 82]. Using a microfluidic real-time PCR amplification method, Dupraz et al. [52] detected the presence of Rickettsia endosymbionts and the pathogen Rickettsia helvetica respectively in $81.6 \%(164 / 201)$ and $6.0 \%(3 / 201)$ of ticks from the same study site. Thus, most Rickettsia detected in the present samples likely correspond to the Rickettsia endosymbiont. However, given the low discriminatory power of the $16 \mathrm{~S}$ rRNA gene fragment used, additional molecular information is required to validate this hypothesis. Our data also revealed the presence of the genus Arsenophonus in relatively high abundance. Arsenophonus is one of the most diverse and abundant maternally inherited bacteria reported in arthropods [83-86] but has been rarely reported in ticks [22, 87, 88]. The tick phenotype associated with Arsenophonus infection is 
unknown, but nutritional and protective functions have been linked to the presence of this bacterial genus in haematophagous insects and psyllids $[89,90]$. In addition, Arsenophonus sp. was suggested to reduce insecticide resistance in pest insects [91], while Arsenophonus nasoniae is a sex-ratio modifier in wasps $[88,92]$. Although previously reported in ticks [39, 93-95], the genus Brevibacterium is poorly known. Brevibacterium species occurring in haematophagous arthropods (kissing bugs, sand flies and horn flies) have been simply described as non-pathogenic bacteria with low abundance [96-98]. However, the recurrent presence of Brevibacterium in diverse unrelated haematophagous arthropods suggests that these bacteria may play a role in blood digestion by their arthropod hosts, and thus possibly in ticks. Experimental work will now be required to test this hypothesis.

Reads corresponding to Rickettsiella were also detected in our samples, but in limited numbers and not in all tick specimens. This situation appears consistent with the exclusion pattern previously reported between this genus and Coxiella-like endosymbionts in Ornithodoros spp. [22]. The absence of Wolbachia genera is also coherent with the study of Duron et al. [22] who did not detect these bacteria in O. maritimus or other Ornithodoros species. As mentioned above, the $16 \mathrm{~S}$ rRNA gene fragment used in the present study did not allow us to go down to the species level and thus demonstrate the presence of bacterial pathogens (e.g. Kocuria, Rickettsia and Rickettsiella). However, we did not detect sequences for the following bacterial genera, which frequently include pathogenic species: Anaplasma, Bartonella, Borrelia, Ehrlichia and Francisella. The absence of these genera is consistent with their low prevalence or absence in adult ticks from the same site [52]. Interestingly, the absence of the Borrelia genus in our data contrasts with its molecular detection (by PCR with $99 \%$ sequence identity with Borrelia turicatae an agent of relapsing fever) in O. maritimus parasitising the Mediterranean storm petrel (Hydrobates pelagicus) from Espartar Island (Balearic archipelago, Spain) [57]. This difference suggests microbial variation according to the considered vertebrate host and/or geographical region where ticks are sampled.

Our study demonstrates that bacterial diversity increases throughout tick development. This pattern is best explained by the acquisition of bacterial taxa through environmental contamination and/or infection during successive blood meals. These results contrast with studies reporting low bacterial diversity in adult hard tick species compared with larvae or nymphs [31, 38, 95, 99]; such reports may result from technical issues associated with relative abundance of different bacterial species (see below) and/or host factors such as the nature of bloodmeal species [31, 38, 99].

Our data also show that bacterial diversity in $O$. maritimus differs according to sex, with females displaying lower bacterial diversity than males. These results are consistent with studies carried out on hard ticks [40, 44] and a recent study on the soft tick Argas japonicus [20] suggesting that this is a general trend in ticks. Treuren et al. [40] proposed that the low bacterial diversity detected in female Ixodes ticks results from the relative high abundance of Rickettsia that hinders the detection of rare bacterial taxa. Indeed, both Thapa et al. [39] and Brinkerhoff et al. [100] found similar microbial diversities in adult male and female Ixodes scapularis after the in silico removal of Rickettsia sequences from bacterial communities. In our study, we found that Rickettsia are abundant in both males and females (females $17.0 \%$ of reads, range $0.0-40.4 \%$; males $3.2 \%$ of reads, range $0.0-15.7 \%$ ) and that Coxiella are significantly more abundant in females than in males (females $36.0 \%$ of reads, range $21.3-59.1 \%$; males $26.4 \%$ of reads, range $14.6-49.3 \%$ ). The high abundance of Coxiella in females is consistent with previous reports for some hard tick species [33, 37, 95]. In our study, the in silico removal of Coxiella and/or Rickettsia sequences did not alter the relative patterns of diversity; males continued to show higher alpha diversity compared with females.

The construction of bacterial networks allowed us to characterise major bacterial interactions in $O$. maritimus. The generated networks indicated that co-occurrence (positive correlation) was more frequent than co-exclusion (negative correlation). Bacterial interactions also appeared to be distinct across developmental stages, with the number of nonrandom interactions increasing through tick development. The increase in network complexity over development correlates with increasing bacterial diversity. However, additional investigations are now required to obtain comparable data for each life stage (larva, nymph and adult) from distinct geographic locations in order to strengthen our conclusions and test the link between bacterial diversity and network complexity. In addition, as tick's microbiota also depend on the environment [17] and bloodmeals [7], future work should be conducted under laboratory conditions [95] in order to control for confounding factors which may blur our understanding of microbial interactions.

Despite developmental changes, our analyses show that some bacterial interactions are stable throughout the life of a tick, regardless of its sex. For example, positive interactions between Brevibacterium and Staphylococcus and between Coxiella and Arsenophonus were found in almost all bacterial networks. In keeping with the concept of a core microbiome, we propose here that there are also core microbial interactions that are maintained throughout development with potentially important biological functions. The case of Coxiella and Arsenophonus is particularly illustrative: these two symbionts are vertically transmitted from mother to offspring through the egg cytoplasm [58, 87]. This co-inheritance suggests that their long-term and stable coexistence in ticks is probable and may be essential for tick survival. 
In the present study, we investigated the bacterial diversity harboured by $O$. maritimus hosted by a single seabird species (L. michahellis) in one colony (Carteau Islet). However, O. maritimus and other Ornithodoros species can parasitise a large range of seabird species [53, 101]. These ticks depend completely on their vertebrate hosts for dispersal among colonies, and even potentially among nests within a colony [101, 102]. For these reasons, Ornithodoros ticks constitute a relevant model for future studies to explore the effect of the vertebrate host species and sampling region on the composition of tick microbiota. In the present study, bacterial diversity was characterized with Illumina sequencing of the bacterial $16 \mathrm{~S}$ rRNA V3-V4 hypervariable region. Even if this technology allows us to have an overview of the majority of bacterial taxa evolving in ticks, it may still underestimate total diversity due to differences in detectability among bacterial groups due to primer choice [103, 104] or taxonomic annotation errors linked to the chosen reference database [105]. Thus, future studies in this system should both compare alternative protocols at the within-population level to account for potential detection biases and apply the same technique across geographic locations and host species to ensure robust comparisons of overall bacterial diversity and the role of different factors in shaping microbial interactions over a tick's lifetime.

It is important to emphasize that we investigated bacterial interactions from NGS reads and microbial network inferences. Despite recent technological advances, understanding complex microbial relationships remain challenging and microbial network inferences present some computational limitations [74, 106-108]. In addition, microbial networks do not provide information on the biological nature of interactions. Thus, experimental investigations are now required to specifically test the biological basis of the positive and negative interactions between taxa that we found here. Hypotheses on the nature of these interactions could be provided by conducting descriptive analyses on different tick tissues [29, 109]. Indeed, the detection of bacterial taxa in the same tissue(s) (e.g. midguts, salivary glands, reproductive tissues, etc.) could be indicative of direct interaction. Alternatively, the use of fluorescent in situ hybridisation (FISH) [110, 111] would allow us to localise bacterial taxa within tick organs and would hence provide relevant information regarding cooccurrence or co-exclusion [112]. In ticks, the bestdocumented examples for co-exclusion involve Coxiella and Francisella, both of which have a pronounced tropism for ovaries and Malpighian tubules [18, 113, 114]. This type of tropism is considered indicative of a high level of lifestyle specialisation towards mutualism; infection of the ovaries suggests transovarian transmission, whereas infection of the Malpighian tubules suggests a nutritional function [18, 113, 114]. In this way, experimental studies could illuminate the mechanisms and biological significance of the bacterial interactions that we uncovered in the present study.
Acknowledgements We thank Marlène Dupraz, Orianne Tournayre, Florian Binetruy, Jonathan D'Ambrosio and others that helped sample ticks in 2015. We thank Audrey Dubost, David Wilkinson, Muriel Dietrich and Colette Cordonin for their help in sequence analyses.

Data Accessibility The bacterial sequence reads produced in this study have been deposited in NCBI Sequence Reads Archive (SRA) (https:// www.ncbi.nlm.nih.gov/sra) under the accession number PRJNA590124.

Author Contributions Karen D. McCoy and Pablo Tortosa contributed equally to this work. Karen D. McCoy and Pablo Tortosa designed the study. Marion Vittecoq, Thomas Blanchon, Karen D. McCoy and Céline Toty organised fieldwork and collected the samples. Céline Toty per formed DNA extractions. Yann Gomard and Olivier Flores analysed the data. Yann Gomard, Olivier Flores, Karen D. McCoy, Pablo Tortosa, Olivier Duron and Patrick Mavingui wrote the paper. All the authors read and approved the final manuscript.

Funding This study was funded by the Agence Nationale de la Recherche (ANR), grant ESPEVEC (ANR blanc ANR 13 BSV7 0018 01) and an exploratory research grant 'DISTIC' from the Labex CeMEB (Centre Méditerranéen de l'Environnement et de la Biodiversité) to Karen D. McCoy. We also thank the 'Tiques et Maladies à tiques' Working Group of the Réseau Ecologie des Interactions Durables (REID) for stim ulating discussions and support. Yann Gomard was supported by a post doctoral fellowship provided by IRD (Institut de Recherche pour le Développement). Sequence analyses were performed using the University of Reunion Island supercomputer facility.

\section{Compliance with Ethical Standards}

Conflict of Interest The authors declare that they have no conflict of interest.

Ethics Approval Permission for tick collection was provided by DDTM 13/Service Mer Eau Environnement/Pôle Nature et Territoires n ${ }^{\circ} 13$ 20180222003 and under the approval of the Grand Port Maritime de Marseille within the context of the project ESPEVEC (ANR 13 BSV7 0018).

\section{References}

1. Dheilly NM (2014) Holobiont holobiont interactions: redefining host parasite interactions. PLoS Path 10:e1004093. https://doi. org/10.1371/journal.ppat.1004093

2. Rosenberg E, Zilber Rosenberg I (2011) Symbiosis and develop ment: the hologenome concept. Birth Defects Research C Embryo Today 93:56 66. https://doi.org/10.1002/bdrc.20196

3. Rosenberg E, Zilber Rosenberg I (2018) The hologenome concept of evolution after 10 years. Microbiome 6:78. https://doi.org/10. 1186/s4016801804579

4. Bennett GM, Moran NA (2015) Heritable symbiosis: the advan tages and perils of an evolutionary rabbit hole. Proc. Natl. Acad. Sci. U. S. A. 112:10169 10176. https://doi.org/10.1073/pnas. 1421388112

5. Moran NA, McCutcheon JP, Nakabachi A (2008) Genomics and evolution of heritable bacterial symbionts. Annu. Rev. Genet. 42: 165 190. https://doi.org/10.1146/annurev.genet.41.110306. 130119

6. Wernegreen JJ (2004) Endosymbiosis: lessons in conflict resolu tion. PLoS Biol. 2:e68. https://doi.org/10.1371/journal.pbio. 0020068 
7. Greay TL, Gofton AW, Paparini A, Ryan UM, Oskam CL, Irwin PJ (2018) Recent insights into the tick microbiome gained through next generation sequencing. Parasit. Vectors 11:12. https://doi. org/10.1186/s13071 01725505

8. Lawrence AL, Hii S F, Chong R et al (2015) Evaluation of the bacterial microbiome of two flea species using different DNA isolation techniques provides insights into flea host ecology. FEMS Microbiol Ecol 91:fiv134. https://doi.org/10.1093/femsec/ fiv134

9. Minard G, Tran FH, Van VT et al (2015) French invasive Asian tiger mosquito populations harbor reduced bacterial microbiota and genetic diversity compared to Vietnamese autochthonous rel atives. Front. Microbiol. 6:970. https://doi.org/10.3389/fmicb. 2015.00970

10. Vasconcelos EJR, Billeter SA, Jett LA, Meinersmann RJ, Barr MC, Diniz PPVP, Oakley BB (2018) Assessing cat flea microbiomes in northern and southern California by 16S rRNA next generation sequencing. Vector Borne Zoonotic Dis 18:491 499. https://doi.org/10.1089/vbz.2018.2282

11. Estrada Peña A, de la Fuente J, Ostfeld RS, Cabezas Cruz A (2015) Interactions between tick and transmitted pathogens evolved to minimise competition through nested and coherent networks. Sci. Rep. 5:10361. https://doi.org/10.1038/srep10361

12. Hegde S, Khanipov K, Albayrak L, Golovko G, Pimenova M, Saldaña MA, Rojas MM, Hornett EA, Motl GC, Fredregill CL, Dennett JA, Debboun M, Fofanov Y, Hughes GL (2018) Microbiome interaction networks and community structure from laboratory reared and field collected Aedes aegypti, Aedes albopictus, and Culex quinquefasciatus mosquito vectors. Front. Microbiol. 9:2160. https://doi.org/10.3389/fmicb 2018.02160

13. Brites Neto J, Duarte KMR, Martins TF (2015) Tick borne infec tions in human and animal population worldwide. Vet World 8: 301 315. https://doi.org/10.14202/vetworld.2015.

14. Dantas Torres F, Chomel BB, Otranto D (2012) Ticks and tick borne diseases: a one health perspective. Trends Parasitol. 28: 437 446. https://doi.org/10.1016/j.pt.2012.07.003

15. Díaz Sánchez S, Estrada Peña A, Cabezas Cruz A, de la Fuente J (2019) Evolutionary insights into the tick hologenome. Trends Parasitol. 35:725 737. https://doi.org/10.1016/j.pt.2019.06.014

16. Narasimhan S, Fikrig E (2015) Tick microbiome: the force within. Trends Parasitol. 31:315 323. https://doi.org/10.1016/j.pt.2015. 03.010

17. Binetruy F, Dupraz M, Buysse M, Duron O (2019) Surface ster ilization methods impact measures of internal microbial diversity in ticks. Parasit. Vectors 12:268. https://doi.org/10.1186/s13071 01935175

18. Duron O, Morel O, Noël V, Buysse M, Binetruy F, Lancelot R, Loire E, Ménard C, Bouchez O, Vavre F, Vial L (2018) Tick bacteria mutualism depends on $\mathrm{B}$ vitamin synthesis pathways. Curr. Biol. 28:1896 1902. https://doi.org/10.1016/j.cub.2018.04. 038

19. Wilkinson DA, Dietrich M, Lebarbenchon C, Jaeger A, le Rouzic C, Bastien M, Lagadec E, McCoy KD, Pascalis H, le Corre M, Dellagi K, Tortosa P (2014) Massive infection of seabird ticks with bacterial species related to Coxiella burnetii. Appl. Environ. Microbiol. 80:3327 3333. https://doi.org/10.1128/AEM.00477 14

20. Yan P, Qiu Z, Zhang T, Li Y, Wang W, Li M, Yu Z, Liu J (2019) Microbial diversity in the tick Argas japonicus (Acari: Argasidae) with a focus on Rickettsia pathogens. Med. Vet. Entomol. 33:327 335. https://doi.org/10.1111/mve.12373

21. Bonnet SI, Binetruy F, Hernández Jarguín AM, Duron O (2017) The tick microbiome: why non pathogenic microorganisms matter in tick biology and pathogen transmission. Front. Cell. Infect. Microbiol. 7:236. https://doi.org/10.3389/fcimb.2017.00236
22. Duron O, Binetruy F, Noël V, Cremaschi J, McCoy KD, Arnathau C, Plantard O, Goolsby J, Pérez de León AA, Heylen DJA, van Oosten AR, Gottlieb Y, Baneth G, Guglielmone AA, Estrada Peña A, Opara MN, Zenner L, Vavre F, Chevillon C (2017) Evolutionary changes in symbiont community structure in ticks. Mol. Ecol. 26:2905 2921. https://doi.org/10.1111/mec.14094

23. Gottlieb Y, Lalzar I, Klasson L (2015) Distinctive genome teduction tates tevealed by genomic analyses of two Coxiella like endosymbionts in ticks. Genome Biol Evol 7:1779 1796. https:// doi.org/10.1093/gbe/evv108

24. Guizzo MG, Parizi LF, Nunes RD, Schama R, Albano RM, Tirloni L, Oldiges DP, Vieira RP, Oliveira WHC, Leite MS, Gonzales SA, Farber M, Martins O, Vaz Jr IS, Oliveira PL (2017) A Coxiella mutualist symbiont is essential to the develop ment of Rhipicephalus microplus. Sci. Rep. 7:17554. https://doi. org/10.1038/s41598 $01717309 \mathrm{x}$

25. Smith TA, Driscoll T, Gillespie JJ, Raghavan R (2015) A Coxiella like endosymbiont is a potential vitamin source for the lone star tick. Genome Biol Evol 7:831 838. https://doi.org/10. 1093/gbe/evv016

26. Engelstädter J, Hurst GDD (2009) The ecology and evolution of microbes that manipulate host reproduction. Annual Rev Ecol Evol Syst 40:127 149. https://doi.org/10.1146/annurev.ecolsys. 110308.120206

27. Ferrari J, Vavre F (2011) Bacterial symbionts in insects or the story of communities affecting communities. Philosophical Transactions of the Royal Society B: Biological Sciences 366: 1389 1400. https://doi.org/10.1098/rstb.2010.0226

28. Jaenike J (2012) Population genetics of beneficial heritable sym bionts. Trends Ecol. Evol. 27:226 232. https://doi.org/10.1016/j. tree.2011.10.005

29. Andreotti R, Pérez de León AA, Dowd SE, Guerrero FD, Bendele KG, Scoles GA (2011) Assessment of bacterial diversity in the cattle tick Rhipicephalus (Boophilus) microplus through tag encoded pyrosequencing. BMC Microbiol. 11:6. https://doi.org/ 10.1186/14712180116

30. Carpi G, Cagnacci F, Wittekindt NE, Zhao F, Qi J, Tomsho LP, Drautz DI, Rizzoli A, Schuster SC (2011) Metagenomic profile of the bacterial communities associated with Ixodes ricinus ticks. PLoS One 6:e25604. https://doi.org/10.1371/journal.pone. 0025604

31. Clow KM, Weese JS, Rousseau J, Jardine CM (2018) Microbiota of field collected Ixodes scapularis and Dermacentor variabilis from eastern and southern Ontario, Canada. Ticks Tick Borne Dis 9:235 244. https://doi.org/10.1016/j.ttbdis.2017.09.009

32. Duan D, Cheng T (2017) Determination of the microbial commu nity features of Haemaphysalis flava in different developmental stages by high throughput sequencing. J. Basic Microbiol. 57: 302 308. https://doi.org/10.1002/jobm.201600557

33. Fryxell RTT, DeBruyn JM (2016) The microbiome of ehrlichia infected and uninfected lone star ticks (Amblyomma americanum). PLoS One 11:e0146651. https://doi.org/10.1371/journal.pone. 0146651

34. Gall CA, Scoles GA, Magori K, Mason KL, Brayton KA (2017) Laboratory colonization stabilizes the naturally dynamic microbiome composition of field collected Dermacentor andersoni ticks. Microbiome 5:133. https://doi.org/10.1186/ s401680170352 9

35. Khoo J J, Chen F, Kho KL, Ahmad Shanizza AI, Lim FS, Tan KK, Chang LY, AbuBakar S (2016) Bacterial community in Haemaphysalis ticks of domesticated animals from the Orang Asli communities in Malaysia. Ticks Tick Borne Dis 7:929 937. https://doi.org/10.1016/j.ttbdis.2016.04.013

36. Lalzar I, Harrus S, Mumcuoglu KY, Gottlieb Y (2012) Composition and seasonal variation of Rhipicephalus turanicus and Rhipicephalus sanguineus bacterial communities. Appl. 
Environ. Microbiol. 78:4110 4116. https://doi.org/10.1128/ AEM.00323 12

37. René Martellet M, Minard G, Massot R et al (2017) Bacterial microbiota associated with Rhipicephalus sanguineus (s.l.) ticks from France, Senegal and Arizona. Parasit Vectors 10:416. https:// doi.org/10.1186/s13071 01723529

38. Swei A, Kwan JY (2017) Tick microbiome and pathogen acqui sition altered by host blood meal. ISME J 11:813 816 . https://doi. org/10.1038/ismej.2016.152

39. Thapa S, Zhang Y, Allen MS (2018) Effects of temperature on bacterial microbiome composition in Ixodes scapularis ticks. MicrobiologyOpen 8:e719. https://doi.org/10.1002/mbo3.719

40. Treuren WV, Ponnusamy L, Brinkerhoff RJ et al (2015) Variation in the microbiota of Ixodes ticks with regard to geography, species, and sex. Appl. Environ. Microbiol. 81:6200 6209. https://doi.org/ 10.1128/AEM.01562 15

41. Zolnik CP, Falco RC, Daniels TJ, Kolokotronis S O (2018) Transient influence of blood meal and natural environment on blacklegged tick bacterial communities. Ticks Tick Borne Dis 9: 563 572. https://doi.org/10.1016/j.ttbdis.2018.01.007

42. Aivelo T, Norberg A, Tschirren B (2019) Human pathogen co occurrence in Ixodes ricinus ticks: effects of landscape topogra phy, climatic factors and microbiota interactions. BioRxiv 559245. https://doi.org/10.1101/559245

43. Estrada Peña A, Cabezas Cruz A, Pollet T, Vayssier Taussat M, Cosson JF (2018) High throughput sequencing and network anal ysis disentangle the microbial communities of ticks and hosts within and between ecosystems. Front. Cell. Infect. Microbiol. 8: 236. https://doi.org/10.3389/fcimb.2018.00236

44. Gurfield N, Grewal S, Cua LS, Torres PJ, Kelley ST (2017) Endosymbiont interference and microbial diversity of the Pacific coast tick, Dermacentor occidentalis, in San Diego County, California. PeerJ 5:e3202. https://doi.org/10.7717/peerj.3202

45. Williams Newkirk AJ, Rowe LA, Mixson Hayden TR, Dasch GA (2014) Characterization of the bacterial communities of life stages of free living lone star ticks (Amblyomma americanum). PLoS One 9:e102130. https://doi.org/10.1371/journal.pone.0102130

46. Binetruy F, Buysse M, Lejarre Q, Barosi R, Villa M, Rahola N, Paupy C, Ayala D, Duron O (2020) Microbial community struc ture reveals instability of nutritional symbiosis during the evolu tionary radiation of Amblyomma ticks. Mol. Ecol. 29:1016 1029. https://doi.org/10.1111/mec.15373

47. Moutailler S, Moro CV, Vaumourin E et al (2016) Co infection of ticks: the rule rather than the exception. PLoS Negl. Trop. Dis. 10: e0004539. https://doi.org/10.1371/journal.pntd.0004539

48. Gall CA, Reif KE, Scoles GA, Mason KL, Mousel M, Noh SM, Brayton KA (2016) The bacterial microbiome of Dermacentor andersoni ticks influences pathogen susceptibility. ISME J 10: 1846 1855. https://doi.org/10.1038/ismej.2015.266

49. Burgdorfer W, Hayes SF, Mavros AJ (1980) Nonpathogenic rick ettsiae in Dermacentor andersoni: a limiting factor for the distri bution of Rickettsia rickettsii. In: Burgdorfer W, Anacker RL (eds) Rickettsiae and rickettsial diseases. Academic Press, New York, pp 585594

50. Macaluso KR, Sonenshine DE, Ceraul SM, Azad AF (2002) Rickettsial infection in Dermacentor variabilis (Acari: Ixodidae) inhibits transovarial transmission of a second Rickettsia. J. Med. Entomol. 39:809 813. https://doi.org/10.1603/0022 2585 39.6. 809

51. Gray JS, Estrada Peña A, Vial L (2014) Ecology of nidicolous ticks. Biol ticks 2:40 60

52. Dupraz M, Toty C, Devillers E, Blanchon T, Elguero E, Vittecoq M, Moutailler S, McCoy KD (2017) Population structure of the soft tick Ornithodoros maritimus and its associated infectious agents within a colony of its seabird host Larus michahellis. Int
J Parasitol Parasites Wildl 6:122 130. https://doi.org/10.1016/j. ijppaw.2017.05.001

53. Dietrich M, Gómez Díaz E, McCoy KD (2010) Worldwide distri bution and diversity of seabird ticks: implications for the ecology and epidemiology of tick borne pathogens. Vector Borne Zoonotic Dis 11:453 470. https://doi.org/10.1089/vbz.2010.0009

54. Hoogstraal H, Clifford CM, Keirans JE, Kaiser MN, Evans DE (1976) The Ornithodoros (Alectorobius) capensis group (Acarina: Ixodoidea: Argasidae) of the Palearctic and oriental regions. $O$. (A.) maritimus: identity, marine bird hosts, virus infections, and distribution in Western Europe and northwestern Africa. J. Parasitol. $62: 799$ 810. https://doi.org/10.2307/3278964

55. Chastel C, Main AJ, Guiguen C, le Lay G, Quillien MC, Monnat JY, Beaucournu JC (1985) The isolation of Meaban virus, a new Flavivirus from the seabird tick Ornithodoros (Alectorobius) maritimus in France. Arch. Virol. 83:129 140

56. Bosch M, Figuerola J (1999) Detrimental effects of ticks Ornithodoros maritimus on the growth of yellow legged Gull Larus michahellis chicks. Ardea 87:83 89

57. Sanz Aguilar A, Payo Payo A, Rotger A, Yousfi L, Moutailler S, Beck C, Dumarest M, Igual JM, Miranda MÁ, Viñas Torres M, Picorelli V, Gamble A, Boulinier T (2020) Infestation of small seabirds by Ornithodoros maritimus ticks: effects on chick body condition, reproduction and associated infectious agents. Ticks Tick Borne Dis 11:101281. https://doi.org/10.1016/j.ttbdis.2019. 101281

58. Duron O, Noël V, McCoy KD et al (2015) The recent evolution of a maternally inherited endosymbiont of ticks led to the emergence of the Q fever pathogen, Coxiella burnetii. PLoS Path 11: e1004892. https://doi.org/10.1371/journal.ppat.1004892

59. Duron O, Jourdain E, McCoy KD (2014) Diversity and global distribution of the Coxiella intracellular bacterium in seabird ticks. Ticks Tick Borne Dis 5:557 563. https://doi.org/10.1016/j.ttbdis. 2014.04.003

60. Chastel C, Launay H, Rogues G, Beaucournu J (1979) Isolement en France du virus Soldado (arbovirus, groupe Hughes) à partir d'Ornithodoros (A.) maritimus Vermeil et Marguet 1967. C R Acad Sci Paris 288:559 561

61. Converse JD, Hoogstraal H, Moussa MI et al (1975) Soldado virus (Hughes group) from Ornithodoros (Alectorobius) capensis (Ixodoidea: Argasidae) infesting sooty tern colonies in the Seychelles, Indian Ocean. Am J Trop Med Hyg 24:1010c1018

62. Arnal A, Gómez Díaz E, Cerdà Cuéllar M, Lecollinet S, Pearce Duvet J, Busquets N, García Bocanegra I, Pagès N, Vittecoq M, Hammouda A, Samraoui B, Garnier R, Ramos R, Selmi S, González Solís J, Jourdain E, Boulinier T (2014) Circulation of a Meaban like virus in yellow legged gulls and seabird ticks in the Western Mediterranean basin. PLoS One 9:e89601. https://doi. org/10.1371/journal.pone.0089601

63. Magoč T, Salzberg SL (2011) FLASH: fast length adjustment of short reads to improve genome assemblies. Bioinformatics 27: 2957 2963. https://doi.org/10.1093/bioinformatics/btr507

64. Schloss PD, Westcott SL, Ryabin T, Hall JR, Hartmann M, Hollister EB, Lesniewski RA, Oakley BB, Parks DH, Robinson CJ, Sahl JW, Stres B, Thallinger GG, van Horn DJ, Weber CF (2009) Introducing mothur: open source, platform independent, community supported software for describing and comparing mi crobial communities. Appl. Environ. Microbiol. 75:7537 7541. https://doi.org/10.1128/AEM.01541 09

65. Kozich JJ, Westcott SL, Baxter NT, Highlander SK, Schloss PD (2013) Development of a dual index sequencing strategy and curation pipeline for analyzing amplicon sequence data on the MiSeq Illumina sequencing platform. Appl. Environ. Microbiol. 79:5112 5120. https://doi.org/10.1128/AEM.01043 13

66. Edgar RC, Haas BJ, Clemente JC, Quince C, Knight R (2011) UCHIME improves sensitivity and speed of chimera detection. 
Bioinformatics 27:2194 2200. https://doi.org/10.1093/ bioinformatics/btr381

67. Westcott SL, Schloss PD (2017) OptiClust, an improved method for assigning amplicon based sequence data to operational taxo nomic units. mSphere 2:e0073 17. https://doi.org/10.1128/ mSphereDirect.00073 17

68. Quast C, Pruesse E, Yilmaz P, Gerken J, Schweer T, Yarza P, Peplies J, Glöckner FO (2013) The SILVA ribosomal RNA gene database project: improved data processing and web based tools. Nucleic Acids Res. 41:D590 D596. https://doi.org/10.1093/nar/ gks1219

69. Good IJ (1953) The population frequencies of species abd the estimation of population parameters. Biometrika 40:237 264 . https://doi.org/10.1093/biomet/40.3 4.237

70. Jost L (2006) Entropy and diversity. Oikos 113:363 375

71. Giraudoux P (2018) Pgirmess: spatial analysis and data mining for field ecologists. R package version 1.6.9. https://CRAN.R project. org $/$ package $=$ pgirmess

72. Core Team R (2017) R: a language and environment for statistical computing. R Foundation for Statistical Computing, Vienna, Austria

73. Segata N, Izard J, Waldron L, Gevers D, Miropolsky L, Garrett WS, Huttenhower C (2011) Metagenomic biomarker discovery and explanation. Genome Biol. 12:R60. https://doi.org/10.1186/ gb 2011126 r60

74. Faust K, Raes J (2016) CoNet app: inference of biological associ ation networks using Cytoscape. F1000Research 5:1519. https:// doi.org/10.12688/f1000research.9050.2

75. Shannon P, Markiel A, Ozier O, Baliga NS, Wang JT, Ramage D, Amin N, Schwikowski B, Ideker T (2003) Cytoscape: a software environment for integrated models of biomolecular interaction networks. Genome Res. 13:2498 2504. https://doi.org/10.1101/ gr. 1239303

76. Brown MB (1975) 400: a method for combining non independent, one sided tests of significance. Biometrics 31:987 992. https:// doi.org $/ 10.2307 / 2529826$

77. Benjamini Y, Hochberg Y (1995) Controlling the false discovery rate: a practical and powerful approach to multiple testing. J R Stat Soc Series B Stat Methodol 57:289 300

78. Salter SJ, Cox MJ, Turek EM, Calus ST, Cookson WO, Moffatt MF, Turner P, Parkhill J, Loman NJ, Walker AW (2014) Reagent and laboratory contamination can critically impact sequence based microbiome analyses. BMC Biol. 12:87. https://doi.org/ 10.1186/s12915 0140087 z

79. Dietrich M, Kearney T, Seamark ECJ, Markotter W (2016) The excreted microbiota of bats: evidence of niche specialization based on multiple body habitats. FEMS Microbiol Lett:fnw284. https:// doi.org/10.1093/femsle/fnw284

80. Jankowski S (2020) MultNonParam: multivariate nonparametric methods. R package version 1(3):4 https://CRAN.R project.org/ package $=$ MultNonParam

81. Perlman SJ, Hunter MS, Zchori Fein E (2006) The emerging di versity of Rickettsia. Proc. R. Soc. B Biol. Sci. 273:2097 2106. https://doi.org/10.1098/rspb.2006.3541

82. Weinert LA, Werren JH, Aebi A, Stone GN, Jiggins FM (2009) Evolution and diversity of Rickettsia bacteria. BMC Biol. 7:6. https://doi.org/10.1186/1741 700776

83. Duron O, Schneppat UE, Berthomieu A, Goodman SM, Droz B, Paupy C, Obame Nkoghe J, Rahola N, Tortosa P (2014) Origin, acquisition and diversification of heritable bacterial endosymbi onts in louse flies and bat flies. Mol. Ecol. 23:2105 2117. https:// doi.org/10.1111/mec.12704

84. Duron O, Bouchon D, Boutin S, Bellamy L, Zhou L, Engelstädter J, Hurst GD (2008) The diversity of reproductive parasites among arthropods: Wolbachia do not walk alone. BMC Biol. 6:27. https://doi.org/10.1186/1741 7007627
85. Jousselin E, Coeur d'Acier A, Vanlerberghe Masutti F, Duron O (2013) Evolution and diversity of Arsenophonus endosymbionts in aphids. Mol. Ecol. 22:260 270. https://doi.org/10.1111/mec. 12092

86. Nováková E, Hypsa V, Moran NA (2009) Arsenophonus, an emerging clade of intracellular symbionts with a broad host dis tribution. BMC Microbiol. 9:143. https://doi.org/10.1186/1471 21809143

87. Clay K, Klyachko O, Grindle N et al (2008) Microbial communi ties and interactions in the lone star tick, Amblyomma americanum. Mol. Ecol. 17:4371 4381. https://doi.org/10.1111/ j.1365 294X.2008.03914.X

88. Grindle N, Tyner JJ, Clay K, Fuqua C (2003) Identification of Arsenophonus type bacteria from the dog tick Dermacentor variabilis. J. Invertebr. Pathol. 83:264 266. https://doi.org/10. 1016/S0022 2011(03)00080 6

89. Dale C, Beeton M, Harbison C, Jones T, Pontes M (2006) Isolation, pure culture, and characterization of "Candidatus Arsenophonus arthropodicus," an intracellular secondary endo symbiont from the Hippoboscid louse fly Pseudolynchia canariensis. Appl. Environ. Microbiol. 72:2997 3004. https:// doi.org/10.1128/AEM.72.4.2997 3004.2006

90. Hansen AK, Jeong G, Paine TD, Stouthamer R (2007) Frequency of secondary symbiont infection in an invasive psyllid relates to parasitism pressure on a geographic scale in California. Appl. Environ. Microbiol. 73:7531 7535. https://doi.org/10.1128/ AEM.01672 07

91. Pang R, Chen M, Yue L, Xing K, Li T, Kang K, Liang Z, Yuan L, Zhang W (2018) A distinct strain of Arsenophonus symbiont de creases insecticide resistance in its insect host. PLoS Genet. 14: e1007725. https://doi.org/10.1371/journal.pgen.1007725

92. Werren JH, Skinner SW, Huger AM (1986) Male killing bacteria in a parasitic wasp. Science 231:990 992. https://doi.org/10.1126/ science. 3945814

93. Li C, Cao J, Zhou Y et al (2014) The midgut bacterial flora of laboratory reared hard ticks, Haemaphysalis longicornis, Hyalomma asiaticum, and Rhipicephalus haemaphysaloides. J. Integr. Agric. 13:1766 1771. https://doi.org/10.1016/S2095 3119(13)60517 1

94. Narasimhan S, Rajeevan N, Liu L, Zhao YO, Heisig J, Pan J, Eppler Epstein R, DePonte K, Fish D, Fikrig E (2014) Gut micro biota of the tick vector Ixodes scapularis modulate colonization of the Lyme disease spirochete. Cell Host Microbe 15:58 71. https:// doi.org/10.1016/j.chom.2013.12.001

95. Zhang R, Yu G, Huang Z, Zhang Z (2020) Microbiota assessment across different developmental stages of Dermacentor silvarum (Acari: Ixodidae) revealed stage specific signatures. Ticks Tick Borne Dis 11:101321. https://doi.org/10.1016/j.ttbdis.2019. 101321

96. Hillesland H, Read A, Subhadra B et al (2008) Identification of aerobic gut bacteria from the kala azar vector, Phlebotomus argentipes: a platform for potential paratransgenic manipulation of sand flies. American J Trop Med Hyg 79:881 886. https://doi. org/10.4269/ajtmh.2008.79.881

97. Lopez Ordonez T, Flores López CA, Montejo Lopez R, Cruz Hernandez A, Conners EE (2018) Cultivable bacterial diversity in the gut of the Chagas disease vector Triatoma dimidiata: iden tification of possible bacterial candidates for a paratransgenesis approach. Front. Ecol. Evol. 5:174. https://doi.org/10.3389/fevo. 2017.00174

98. Palavesam A, Guerrero FD, Heekin AM, Wang J, Dowd SE, Sun Y, Foil LD, Pérez de León AA (2012) Pyrosequencing based analysis of the microbiome associated with the horn fly, Haematobia irritans. PLoS One 7:e44390. https://doi.org/10. 1371/journal.pone. 0044390 
99. Kwan JY, Griggs R, Chicana B, Miller C, Swei A (2017) Vertical vs. horizontal transmission of the microbiome in a key disease vector, Ixodes pacificus. Mol. Ecol. 26:6578 6589. https://doi. org $/ 10.1111 /$ mec. 14391

100. Brinkerhoff RJ, Clark C, Ocasio K, Gauthier DT, Hynes WL (2020) Factors affecting the microbiome of Ixodes scapularis and Amblyomma americanum. PLoS One 15:e0232398. https:// doi.org/10.1371/journal.pone. 0232398

101. Gómez Díaz E, Morris Pocock JA, González Solís J, McCoy KD (2012) Trans oceanic host dispersal explains high seabird tick di versity on Cape Verde islands. Biol. Lett. 8:616 619. https://doi. org/10.1098/rsbl.2012.0179

102. Rataud A, Dupraz M, Toty C et al (2020) Evaluating functional dispersal in a nest ectoparasite and its eco epidemiological impli cations. Front Vet Sci. (In press) [Reviewed and recommended by Peer Community In Ecology. https://doi.org/10.24072/pci. ecology.100013

103. Klindworth A, Pruesse E, Schweer T, Peplies J, Quast C, Horn M, Glöckner FO (2013) Evaluation of general 16S ribosomal RNA gene PCR primers for classical and next generation sequencing based diversity studies. Nucleic Acids Res. 41:e1. https://doi.org/ 10.1093/nar/gks808

104. Sperling JL, Silva Brandão KL, Brandão MM, Lloyd VK, Dang S, Davis CS, Sperling FAH, Magor KE (2017) Comparison of bacterial 16S rRNA variable regions for microbiome surveys of ticks. Ticks Tick Borne Dis 8:453 461. https://doi.org/10.1016/j. ttbdis.2017.02.002

105. Edgar RC (2018) Taxonomy annotation errors in 16S rRNA and fungal ITS sequence databases. BioRxiv 288654. https://doi.org/ $10.1101 / 288654$

106. Faust K, Raes J (2012) Microbial interactions: from networks to models. Nat Rev Microbiol 10:538 550. https://doi.org/10.1038/ nrmicro2832
107. Layeghifard M, Hwang DM, Guttman DS (2017) Disentangling interactions in the microbiome: a network perspective. Trends Microbiol. 25:217 228. https://doi.org/10.1016/j.tim.2016.11.008

108. Hirano H, Takemoto K (2019) Difficulty in inferring microbial community structure based on co occurrence network approaches. BMC Bioinformatics 20:329. https://doi.org/10.1186/s12859 01929151

109. Zolnik CP, Prill RJ, Falco RC, Daniels TJ, Kolokotronis SO (2016) Microbiome changes through ontogeny of a tick pathogen vector. Mol. Ecol. 25:4963 4977. https://doi.org/10.1111/mec. 13832

110. Moss CE, Robson A, Fikrig E, Narasimhan S (2018) Visualization of microbiota in tick guts by whole mount in situ hybridization. $\mathrm{J}$ Vis Exp:e57758. https://doi.org/10.3791/57758

111. Wang M, Zhu D, Dai J, Zhong Z, Zhang Y, Wang J (2018) Tissue localization and variation of major symbionts in Haemaphysalis longicornis, Rhipicephalus haemaphysaloides and Dermacentor silvarum in China. Appl. Environ. Microbiol. 84:e00029 e00018. https://doi.org/10.1128/AEM.00029 18

112. Moreira LA, Iturbe Ormaetxe I, Jeffery JA, Lu G, Pyke AT, Hedges LM, Rocha BC, Hall Mendelin S, Day A, Riegler M, Hugo LE, Johnson KN, Kay BH, McGraw EA, van den Hurk AF, Ryan PA, O'Neill SL (2009) A Wolbachia symbiont in Aedes aegypti limits infection with dengue, Chikungunya, and Plasmodium. Cell 139:1268 1278. https://doi.org/10.1016/j.cell. 2009.11.042

113. Buysse M, Plantard O, McCoy KD et al (2019) Tissue localization of Coxiella like endosymbionts in three European tick species through fluorescence in situ hybridization. Ticks Tick Borne Dis 10:798 804. https://doi.org/10.1016/j.ttbdis.2019.03.014

114. Lalzar I, Friedmann Y, Gottlieb Y (2014) Tissue tropism and vertical transmission of Coxiella in Rhipicephalus sanguineus and Rhipicephalus turanicus ticks. Environ. Microbiol. 16: 3657 3668. https://doi.org/10.1111/1462 2920.12455 